\title{
Deutsche Chemieunternehmen blicken vorsichtig in die Zukunft
}

Der jüngsten von Ceresana Research durchgeführten Umfrage zufolge schätzen die deutschen auf dem Chemiesektor tätigen Unternehmen die aktuelle Lage auf ihrem Heimatmarkt als relativ stabil ein. Über die Hälfte sieht in Deutschland sogar den Markt mit dem größten Wachstumspotenzial für ihr Unternehmen. Allerdings sorgen Euro- und Schuldenkrise sowie die schwächelnde Weltkonjunktur nach wie vor für Verunsicherung.

O bgleich die wirtschaftliche Lage in Deutschland gegenwärtig als relativ gut eingeschätzt wird, erwarten viele Unternehmen keine weitere Verbesserung in den kommenden Monaten. Der vorsichtige Blick in die Zukunft führt zu einer eher pessimistischen Einschätzung des gegenwärtigen Geschäftsklimas. Der Wert des CIM Barometers für Deutschland liegt mit 2,6 Punkten unter dem globalen Wert von 6,5.

\section{Nachfrage zufriedenstellend}

Da sich ein Großteil der Teilnehmer der CIM-Umfrage vom Herbst 2012 mit der Nachfrage nach ihren Produkten zufrieden zeigt, plant die Mehrheit auch keine Aufstockung des Produktionsvolumens. „In welche Richtung sich diese beiden Indikatoren jedoch entwickeln, hängt sehr stark von der weiteren Entwicklung der Euro- und Schuldenkrise ab“, erklärt Oliver Kutsch, Geschäftsführer von Ceresana. Momentan werde die Wirtschaftsentwicklung aufgrund der vorliegenden Verunsicherung stark gebremst. Trotz der derzeitig angespannten Situation rechnen die Unternehmen nicht mit einem Schrumpfen des von innen bearbeiteten Marktes. Der Großteil geht hier, auch aufgrund der vorliegenden Unsicherheit hinsichtlich eingetrübter Weltkonjunktur und Schuldenproblematik von einer Stagnation aus. Dennoch sieht mehr als jeder 2 . Teilnehmer in Deutschland den Markt mit dem größten Wachstumspotential, obgleich ein Großteil ungünstiger werdende Standortbedingungen erwartet. Um sich dennoch am Markt behaup- ten zu können, setzen mehr als drei von vier deutschen Unternehmen den Schwerpunkt ihrer strategischen Ausrichtung auf Qualitätsführerschaft.

\section{Vertrauen auf Innovationsstärke und Kundentreue}

Ceresana wollte von den Unternehmen auch wissen, mit welchen Maßnahmen sie sich auf kommende Schwächephasen vorbereiten. Präventive Maßnahmen im finanziellen Bereich sind für die Teilnehmer vor allem eine Reduzierung der Sach- und Personalkosten. Des Weiteren setzen rund zwei Drittel auf Kundenbindung und -pflege sowie auf Produktinnovationen, um sich gegen zukünftige Flauten abzusichern.

Weitere Infos: www.ceresana.com/de/ cim

\section{Veranstaltungen adhäsion 1-2/2013}

\begin{tabular}{|c|c|c|c|}
\hline Termin & Ort & Thema & Veranstalter \\
\hline 26.-27.02.2013 & Frankfurt & $\begin{array}{l}\text { 12. Kolloquium: Gemeinsame } \\
\text { Forschung in der Klebtechnik }\end{array}$ & $\begin{array}{l}\text { DECHEMA e.V. } \\
\text { Tel.: +49 (0)69 7564-235, klebtechnik@dechema.de }\end{array}$ \\
\hline 12.- 14.03 .2013 & Paris & JEC & $\begin{array}{l}\text { JEC } \\
\text { Tel.: +33 } 158361500, \text { www.jeccomposites.com }\end{array}$ \\
\hline 19.-21.03.2013 & Nürnberg & ECS European Coatings Show & $\begin{array}{l}\text { NürnbergMesse GmbH } \\
\text { Tel.: +49 (0) } 9118606-0 \text {, www.european-coatings-show.com/de }\end{array}$ \\
\hline 25.-27.03.2013 & Regensburg & $\begin{array}{l}\text { Kleben in der Elektronik - } \\
\text { Grundlagen, Herausforderungen und } \\
\text { Lösungen }\end{array}$ & $\begin{array}{l}\text { OTTI e.V. } \\
\text { Tel: +49 } 941 \text { 29688-34, www.otti.de/veranstaltungen.html }\end{array}$ \\
\hline 08.- 12.04 .2013 & Hannover & Industrial Supply & $\begin{array}{l}\text { Deutsche Messe } \\
\text { Tel.: +49 (0)511 89-31115, www.hannovermesse.de }\end{array}$ \\
\hline 16.-17.04.2013 & Stuttgart & $\begin{array}{l}\text { FTK - Fertigungstechnologie Kleben } \\
2013\end{array}$ & $\begin{array}{l}\text { Adhäsion Kleben \& Dichten } \\
\text { Tel: +49 (0)611 7878-283, www.adhaesion.com }\end{array}$ \\
\hline $16 .-17.04 .2013$ & Stuttgart & Werkstoffe im Automobilbau & $\begin{array}{l}\text { ATZlive } \\
\text { Tel: +49 (0)611 7878-274, www.ATZlive.de }\end{array}$ \\
\hline
\end{tabular}

